Y. B. NGUYEN,Y.NAKANO,N. M. DUGGAN, L. SCOTT, M. BREUGST, D. W. LUPTON* (MONASH UNIVERSITY, CLAYTON, AUSTRALIA AND UNIVERSITÄT ZU KÖLN, GERMANY) $\mathrm{N}-$ Heterocyclic Carbene Catalyzed (5+1) Annulations Exploiting a Vinyl Dianion Synthon Strategy

Angew. Chem. Int. Ed. 2019, 58, 11483-11490.

\title{
(5+1) Annulations through Double Umpolung of Conjugate Acceptors
}

Intramolecular, non-asymmetric reaction:<smiles>CC(C)=CC(=O)C=C1CCC(C)=CS1</smiles>

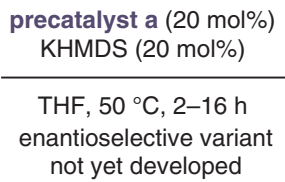

THF, $50{ }^{\circ} \mathrm{C}, 2-16 \mathrm{~h}$

enantioselective variant not yet developed

$\mathrm{EWG}=\mathrm{CO}_{2} \mathrm{Alk}, \mathrm{C}(\mathrm{O}) \mathrm{Alk}, \mathrm{C}(\mathrm{O}) \mathrm{Ar}, \mathrm{CN}$

:

Intermolecular, asymmetric reaction:

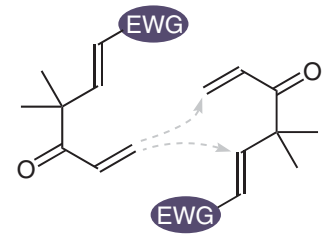

$\mathrm{EWG}=\mathrm{CO}_{2} \mathrm{Alk}, \mathrm{C}(\mathrm{O}) \mathrm{Alk}, \mathrm{C}(\mathrm{O}) \mathrm{Ph}$, $\mathrm{CON}(\mathrm{OMe}) \mathrm{Me}, \mathrm{SO}_{2} \mathrm{Ar}$

\section{precatalyst b (20 mol\%)} KHMDS (20 mol\%)

DCE, $84{ }^{\circ} \mathrm{C}, 2-16 \mathrm{~h}$

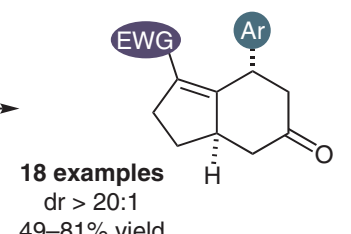

d9-81\% $>20: 1$

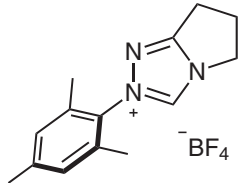

precatalyst a

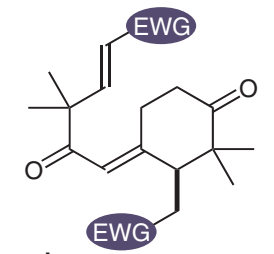

13 examples $61-98 \%$ yield er from $70: 30$ to $98: 2$
Category

Organo- and

Biocatalysis

Key words

N-heterocyclic

carbenes

homoenolates

umpolung

$(5+1)$ annulation

vinyl dianions

alkenes

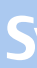

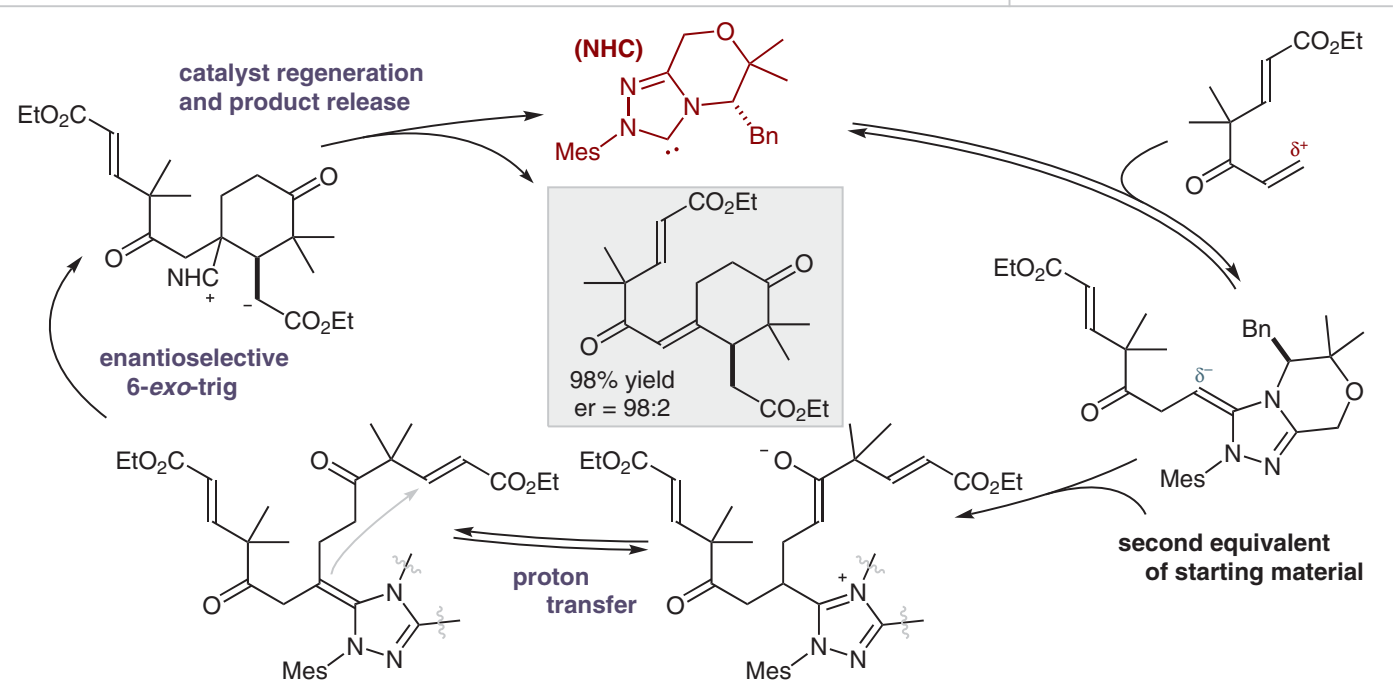

Significance: The Lupton group reports a carbenecatalyzed (5+1) annulation that involves sequential polarity inversion of conjugate acceptors, thereby enabling double functionalization of terminal olefins. A nonasymmetric but highly diastereoselective intramolecular cyclization and an asymmetric dimerization are presented. Both reactions proceed with good to excellent yields, with the latter also achieving very good enantioselectivities.
Comment: Preceding literature reports on consecutive umpolung strategies of Michael acceptors exclusively show uncontrolled dimerization or oligomerization reactions. This is the first work that successfully translates the concept into an enantioselective and high-yielding catalytic method. A possible extension of the protocol to more-general substrate classes or an intermolecular cross-conjugate acceptor coupling would be highly desirable. 